\title{
Existence of microplastics in soil and groundwater in Jiaodong Peninsula
}

\author{
Sheng $\mathrm{Su}^{1,2}$, Sifan Zhou ${ }^{1,2}$, Guoqing $\operatorname{Lin}^{1,2 *}$ \\ ${ }^{1}$ Institute of Coastal Environmental Pollution Control, Key Laboratory of Marine Environment and Ecology, Ministry of Education, \\ ${ }^{2}$ College of Environmental Science and Engineering, Ocean University of China, Qingdao 266100, China
}

\begin{abstract}
Microplastic pollution has become a major global problem demanding prompt solution. So far, most research has focused on marine environment, but there is a lack of information about microplastic distribution, and persistence uptake in coastal soil environment. In this study, the Huangshui River Basin in Laizhou Bay and Dagu River Basin in Jiaozhou Bay of Shandong Province of China was taken as the research area. A total of 3,352 microplastic items were collected from 12 samples from the four sites in this study. The results showed that local soil was already affected by microplastics, of which $92.9 \%$ were particles, $6.1 \%$ were fibers, and only $1 \%$ were films. The existence of film PE indicated that the microplastic pollution in soil probably came from the plastic film. The degree of pollution was correlated with the size, and the size of microplastics was negatively correlated with abundance. Only a few labelled fibers were detected in groundwater samples, which may come from the external environment. This study contributes to a deeper understanding of environmental microplastic pollution in the coastal region.
\end{abstract}

\section{Introduction}

As the economy continues to grow, the demand for plastic products is also increasing. Plastics are cheap and versatile, and have become the main source of industrial raw materials. Statistics show that the world's plastic production scale has expanded to 29.9 billion tons [1]. However, only a small part of them can be recycled[2]. A large number of discarded plastics pose a threat to the ecological environment. Compared with large plastics, microplastics with particle size less than $5 \mathrm{~mm}$ pose a higher threat[3]. China is one of the largest countries in the production and consumption of plastic products[4]. The annual production of plastic waste in China is up to 3 million tons . Although science and technology of human beings have been gradually improved, the growing waste plastics are still discharged into the ocean, threatening the stability of marine ecology.

Microplastics refers to plastic particles with diameter less than $5 \mathrm{~mm}$, which was proposed by Thompson[5] in 2004. The microplastic pollution in the natural environment includes two parts: (1) primary microplastics are used for cosmetics and industrial purposes, and (2) secondary microplastics derive from the fragmentation of larger plastics, such as discarded plastic bags, nylon ropes and other large plastics. Most of the microplastic pollution in the environment comes from secondary microplastic. At present, a number of investigations show that microplastics are commonly found in oceans [6] and lakes [7]. Microplastics not only can exist in the natural environment, but also have entered people's lives. The presence of microplastics was also detected in salt [8] and beer[9]. Currently, microplastics were widely found in global waters, and more and more attentions had been paid to the environmental problems and biological damage caused by microplastics. The potential impact and governance of microplastics have gradually become a research hotspot. However, to realize the distribution of microplastics in groundwater and the damage to agriculture and the impact on ecosystem still needed further research and more endeavors.

\section{Research areas and Methods}

\subsection{Research areas}

The study area comprised Huangshui River in Laizhou Bay and Dagu River in Jiaozhou Bay, Shandong Province, China. Dagu River is the largest river in Jiaozhou Bay of the Yellow Sea in eastern China. Dagu River Basin had an average annual precipitation of $745.5 \mathrm{~mm}$, an average annual runoff depth of $223.2 \mathrm{~mm}$, equivalent to an annual runoff of 929 million cubic meters. Huangshui River is located in the west of Yantai City, Shandong Province. Huangshui River total length of 55 kilometers, the basin area of 1152.53 square kilometers and the annual rainfall of $651.9 \mathrm{~mm}$.

\footnotetext{
* Corresponding author: lingq@ouc.edu.cn
} 


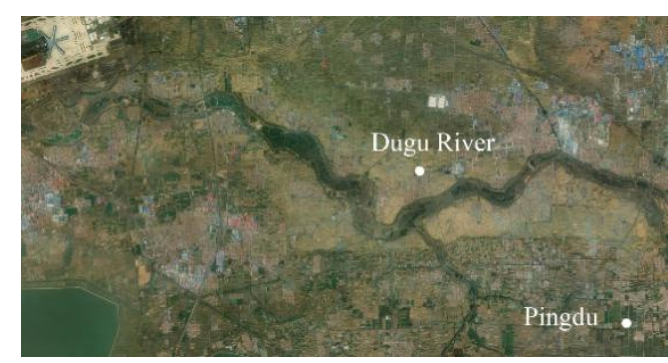

Fig 1 The location of water sampling sites

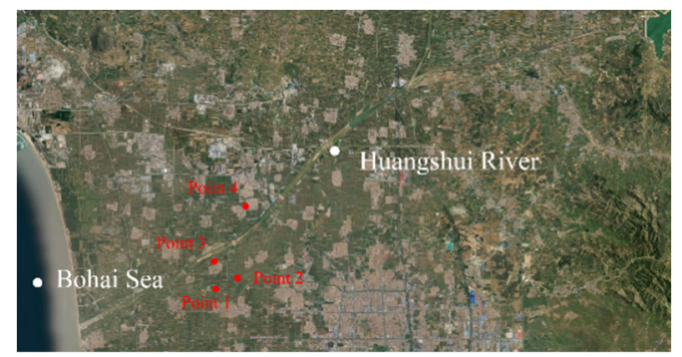

Fig 2 The location of soil sampling sites

\subsection{Methods}

Water samples were filtered by a diaphragm vacuum pump with $0.45 \mu \mathrm{m}$ fiber membrane. The particles collected by the membrane were washed with distilled water and transferred to a Petri dish. Then $10 \mathrm{~mL}$ of $30 \%$ $\mathrm{H}_{2} \mathrm{O}_{2}$ was added and kept at $60{ }^{\circ} \mathrm{C}$ for $1 \mathrm{~h}$ to fully oxidize the organic matter. After oxidation and digestion, the particles were filtered and collected with $0.45 \mu \mathrm{m}$ PC membrane, then 2-3 drops of Nile Red methanol solution were dripped into the whole membrane, and incubated in the dark for $0.5 \mathrm{~h}$ for full staining.

The soil samples were put in the oven for drying, and screened with a $2 \mathrm{~mm}$ sieve to pick out large impurities and visible plastic. Then the plastic was cleaned and stored in the Petri dish. After being screened, $30 \% \mathrm{H}_{2} \mathrm{O}_{2}$ was added to the soil at $60{ }^{\circ} \mathrm{C}$ for $1 \mathrm{~h}$ to fully oxidize and digest the organic matter. The treated soil solution was transferred to a small glass bottle, and was add saturated $\mathrm{NaCl}$ solution. The solution was sonicated for 10 minutes. Successively, the mixture was stirred for $5 \mathrm{~min}$ and left for $24 \mathrm{~h}$. Then, the experimental steps mentioned above were repeated five times. The supernatant was collected and filtered through a $0.45 \mu \mathrm{m}$ membrane filter. The pelleted cells were stained with 2-3 drops of Nile red staining solution and placed in the dark for 0.5 hours to extract.

The filter membrane was observed and photographed under fluorescence microscope with ultraviolet light. Whole fluorescent particles were observed after carefully removing the filter membrane with tweezers and a Fourier infrared (FT-IR) microscopy spectrometer was used to analyze the chemical structure of the samples. The filter membrane was analyzed with ImageJ software and the abundance and particle size of microplastics were recorded.

\section{Results and discussion}

\subsection{The microplastics in soil}

The detection results of microplastics in soil samples by fluorescence microscope were shown in Fig. 3. The main forms of microplastics were particles $(92.9 \%)$, fibers $(6.1 \%)$ and films (1\%). In agricultural soil, the morphology of microplastics was mostly particles. In addition to particles, there were also some fibers and films in agricultural soil. The fibers were likely from domestic water, such as the irrigation of laundry water or the deposition of fibers in the atmosphere, while the films were from the film mulching.

A total of 3,352 microplastic items were collected from 12 samples from the four sites in this study. As presented in Fig.4, size I $(57.9 \%)=20$ to $100 \mu \mathrm{m}$, size II $(38.6 \%)=100$ to $1000 \mu \mathrm{m}$ and size III $(3.50 \%)>1000 \mu \mathrm{m}$. The results confirmed that the microplastic pollution in the soil mainly predominately originated from small particles. Figure 5 illustrated the relationship between size and abundance. In soil the smaller the size was, the greater the microplastic abundance was. With the further fragmentation and decomposition of the microplastic, the soil environment would be damaged.

The abundance of each sampling point was shown in Table 1. The first sampling point was located in the vegetable field beside Yujia village. Increasing in depth resulted in the increasing number of microplastics per sample. The abundance of microplastics at $3 \mathrm{~cm}$ and $6 \mathrm{~cm}$ was similar, but the number of microplastics showed a large increase at $9 \mathrm{~cm}$. It could be concluded that this occurs had strongly with anthropogenic sources in this study area and microplastics were prone to transfer from surface soils to deep soils.

The second sampling point was located in a wheat field. With the increase of depth, the amount of microplastic of each grain size decreased. A large decrease occurred at $3 \mathrm{~cm}-6 \mathrm{~cm}$, and the amount of microplastic at $6 \mathrm{~cm}$ was close to $9 \mathrm{~cm}$. The results showed that microplastic abundance and particle size gradually decreased with the soil sampling depth. At the second sampling point, irrigation water and agricultural plastics were the possible sources of microplastic.

The third sampling point was located in a vineyard. Speculatively, there was a distinctly regional distribution in space. With the increasing of depth, the amount of microplastic first decreased and then increased, with the minimum at $6 \mathrm{~cm}$, followed by $3 \mathrm{~cm}$, and the maximum at $9 \mathrm{~cm}$. The sources of microplastic may be from irrigation water and plastic items.

The fourth sampling point was located in an orchard. The amount of microplastic were similar at different soil depths, but particle size distribution were significant different in in different soil depths. The particle size between $4 \mathrm{~cm}$ and $6 \mathrm{~cm}$ from the soil surface had 20-100 $\mu \mathrm{m}$ diameter, while the $9 \mathrm{~cm}$ from the soil surface had $100-1000 \mu \mathrm{m}$ diameter. In general, it was difficult for the microplastic particles with the large particle size to enter into the deep soil, which might be caused by man-made plowing. 


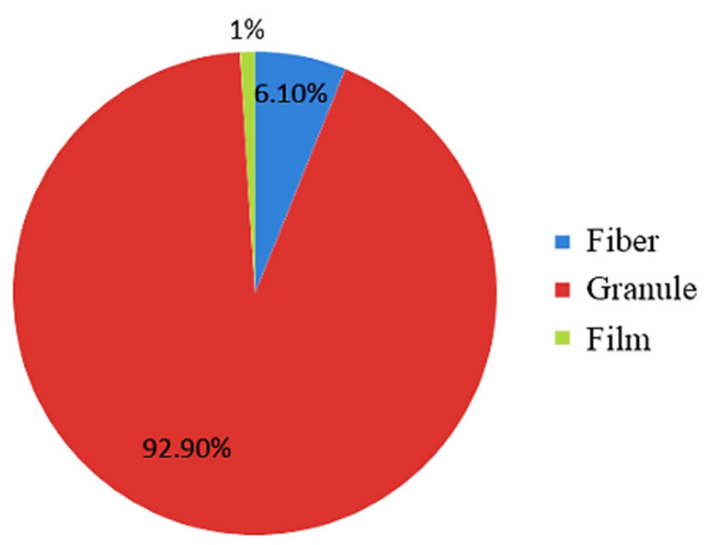

Fig 3 Particle shape ratio of microplastics in soil samples

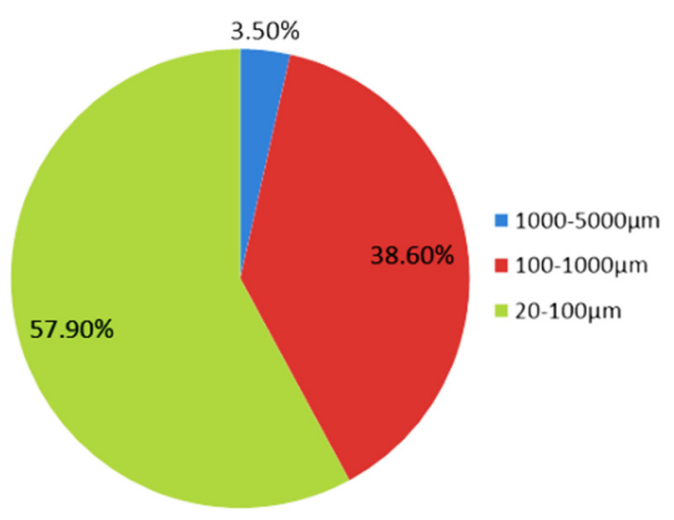

Fig 4 Particle size ratio of microplastics in soil samples

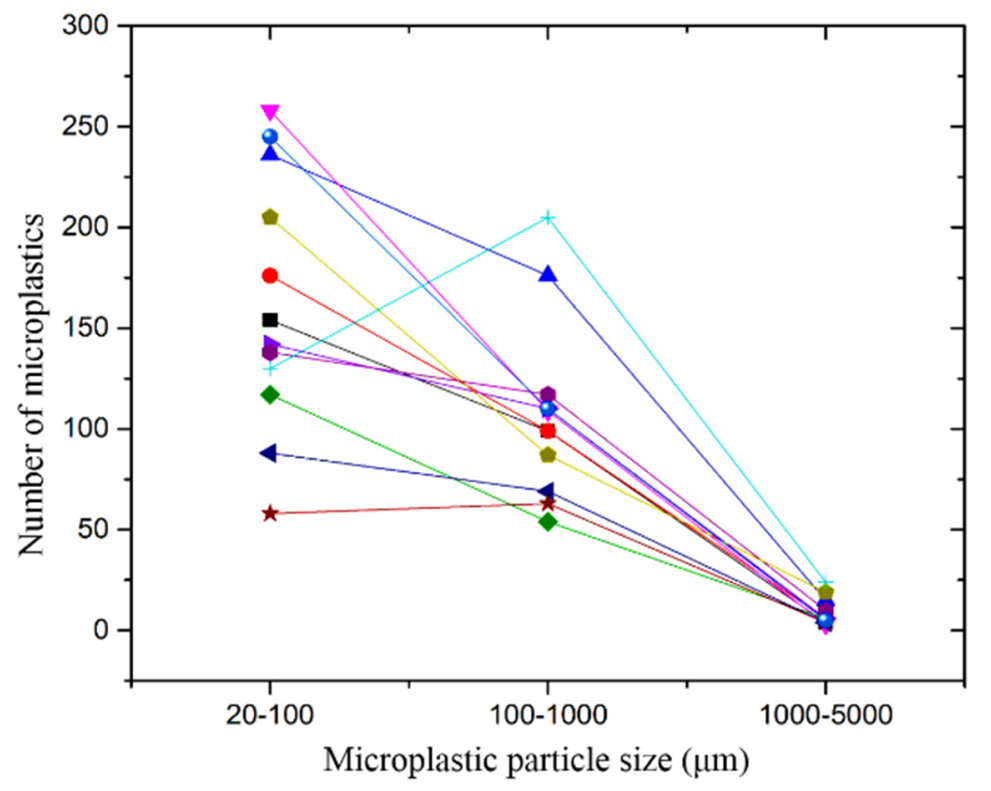

Fig 5 Particle size distribution of microplastics at each sampling point in soil samples

Table 1 Abundance of microplastics at sampling points

\begin{tabular}{|c|c|c|}
\hline $\begin{array}{l}\text { Samplin } \\
\text { g point }\end{array}$ & Depth $(\mathrm{cm})$ & $\begin{array}{l}\text { Total } \\
\text { number }\end{array}$ \\
\hline
\end{tabular}

\begin{tabular}{ccccccc}
\hline \multirow{2}{*}{1} & 3 & 257 & 154 & 99 & 4 & 3 \\
& 6 & 282 & 176 & 100 & 6 & 21 \\
& 9 & 427 & 236 & 176 & 15 & 48 \\
2 & 3 & 370 & 258 & 109 & 3 & 17 \\
& 6 & 177 & 117 & 54 & 6 & 14 \\
& 9 & 161 & 88 & 69 & 4 & 8 \\
3 & 3 & 258 & 142 & 110 & 6 & 27 \\
& 6 & 265 & 138 & 117 & 10 & 20 \\
& 9 & 125 & 58 & 63 & 4 & 17 \\
& 3 & 311 & 205 & 87 & 19 & 14 \\
& 6 & 360 & 245 & 110 & 5 & 4 \\
\hline
\end{tabular}

The structure of the sample was analyzed by comparing the infrared spectra of the sample and the PE. The results were presented in Fig 6 and 7, the antisymmetric and symmetric stretching vibrations around 2916 and $2850 \mathrm{~cm}^{-1}$ peaks were corresponding to $-\mathrm{CH}_{2}$. The peaks located at $1471,719 \mathrm{~cm}^{-1}$ most likely 
reflect the bending vibration of the $-\mathrm{CH}_{2}$ and wagging vibration of the $-\mathrm{CH}_{2}$, respectively. The patterns of the sample show that all the peaks match well with the PE. The samples were initially considered to be polyethylene.

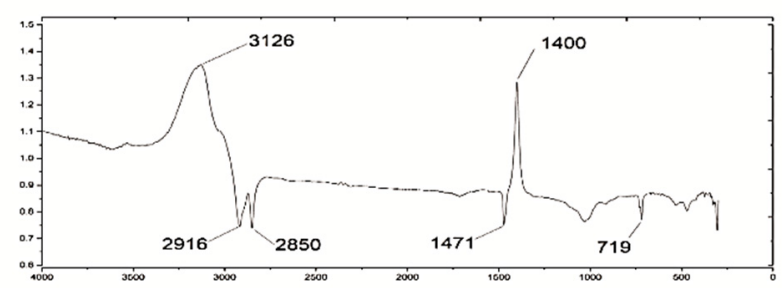

Fig 6 Microplastic spectrum in soil samples

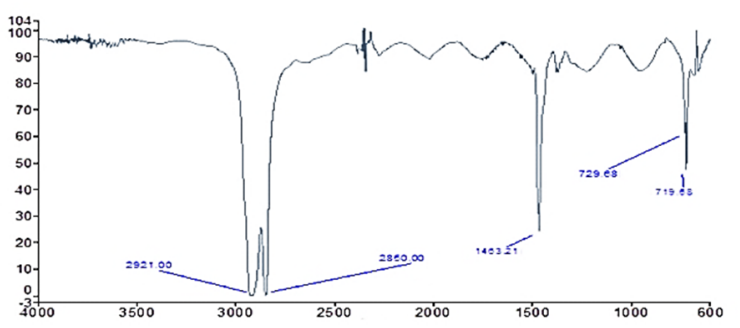

Fig 7 Polyethylene standard spectrum in soil samples

\subsection{The microplastics in groundwater}

In all groundwater samples, only a few labeled fibers were detected. The Fourier infrared (FT-IR) microscopy spectrometer was used to analyze the chemical structure of the samples, as shown in Figure 8. Compared with the characteristic peak of PA (polyamide, i.e. nylon), the absorption peak at around $3278 \mathrm{~cm}^{-1}$ was assigned as the amine groups and the absorption peaks at around $1630 \mathrm{~cm}^{-1}$ and $1531 \mathrm{~cm}^{-1}$ were assigned as the amide. The absorption peaks at $2923 \mathrm{~cm}^{-1}$ and $2853 \mathrm{~cm}^{-1}$ were the peaks of the $-\mathrm{CH}_{2}-\mathrm{CH}_{2}-$ group. The samples were initially considered to be polyamide. Its picture was in Figure 9.

Generally, only particles with diameter less than 1.91 $\mu \mathrm{m}[10]$ could migrate downward through the pores of soil, so the fiber could not enter into groundwater through percolation. While the groundwater samples revealed microplastic contamination[11], there was not universal. The fiber might enter the underground by soil cavities. Therefore, it was concluded that the polyamide (PA) fiber in the groundwater samples would not move down to the groundwater. It was likely that it entered the groundwater from the external environment while collecting water.

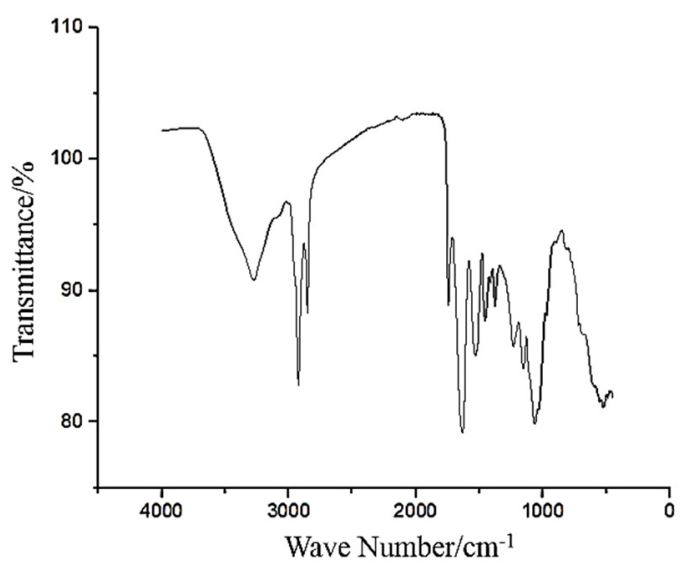

Fig 8 Spectrum of microplastics in groundwater

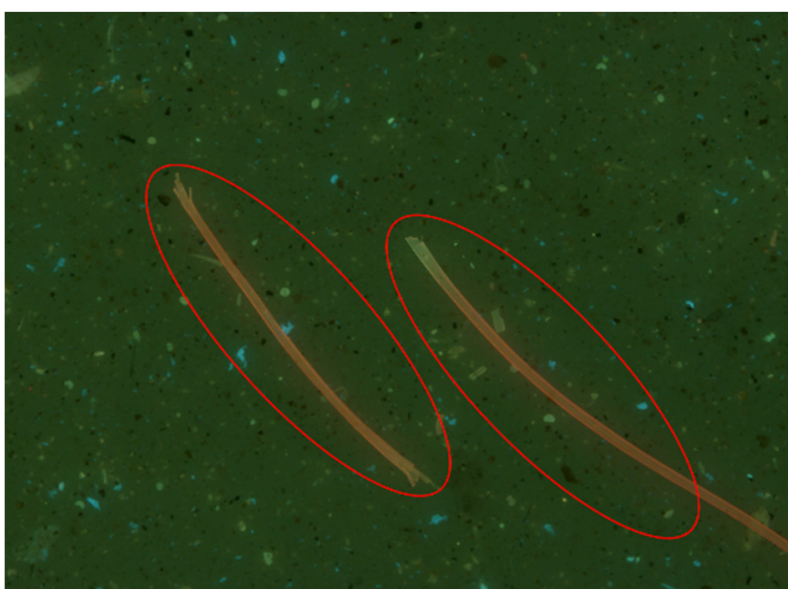

Fig 9 Photo of microplastics in groundwater samples

\section{Conclusions}

(1) A total of 3,352 microplastic items were collected from 12 samples from the four sites in this study. The study showed that the agricultural soil already affected by microplastic pollution, of which $92.9 \%$ were particles, $6.1 \%$ were fibers, and only $1 \%$ were films.

(2) The results confirmed that the microplastic pollution in the soil mainly predominately originated from small particles.

(3) The existence of film PE proved that the microplastic pollution in soil probably come from the plastic film. The severity of pollution caused by the microplastic was correlated with the size, and the size of microplastics was negatively correlated with abundance.

(4) Polyamide existed in ground water. The possible reason for this situation was the pollution of ground water caused by well water. It was necessary to conduct the study about the vertical migration of microplastics in the soil to assess the potential of groundwater contamination by microplastics.

\section{Acknowledgments}

This research was supported by instruments and equipment of the Red Tide Molecular Biology Laboratory of the School of Environmental Science and Engineering, 
Ocean University of China.

\section{References}

1. M. Cai, H. He, M. Liu, S. Li, G. Tang, W. Wang, P. Huang, G. Wei, Y. Lin, B. Chen, J. Hu, Z. Cen, Sci Total Environ. 633, 1206-1216 (2018).

2. O. S. Alimi, J. Farner Budarz, L. M. Hernandez, N. Tufenkji, Environ Sci Technol. 52, 1704-1724 (2018).

3.A. Tarafdar, J. Lee, J. Jeong, H. Lee, Y. Jung, H. B. Oh, H. Y. Woo, J. Kwon, J Hazard Mater. 409, 124516 (2021).

4.J. R. Jambeck, R. Geyer, C. Wilcox, T. R. Siegler, M. Perryman, A. Andrady, R. Narayan, K. L. Law, Science. 347, 768-771 (2015).

5.R. C. Thompson, Science. 304, 838 (2004).

6.M. Eriksen, L. C. M. Lebreton, H. S. Carson, M. Thiel, C. J. Moore, J. C. Borerro, F. Galgani, P. G. Ryan, J. Reisser, Plos One. 9, e111913 (2014).

7.W. Wang, W. Yuan, Y. Chen, J. Wang, Sci Total Environ. 633, 539-545 (2018).

8.M. E. Iñiguez, J. A. Conesa, A. Fullana, Sci Rep-Uk. 7, 6123 (2017).

9.M. Kosuth, S. A. Mason, E. V. Wattenberg, Plos One. 13, e194970 (2018).

10.M. B. McGechan, D. R. Lewis, Biosyst Eng. 83, 255 273 (2002).

11.S. V. Panno, W. R. Kelly, J. Scott, W. Zheng, R. E. McNeish, N. Holm, T. J. Hoellein, E. L. Baranski, Groundwater. 57, 189-196 (2019). 